\title{
Evaluation of Respiratory Dynamics in an Asymmetric Lung Compliance Model
}

\author{
So Hui Yun ${ }^{1}$, Ho-Jin Lee ${ }^{2}$, Yong-Hun Lee ${ }^{3}$, and Jong Cook Park ${ }^{1}$ \\ ${ }^{1}$ Department of Anesthesiology and Pain Medicine, Jeju National University School of Medicine, Jeju; 'Department of Anesthesiology and Pain Medicine, Seoul National University Hospital, Seoul; \\ ${ }^{3}$ Department of Anesthesiology and Pain Medicine, Asan Medical Center, University of Ulsan College of Medicine, Seoul, Korea
}

Background: Unilateral lung hyperinflation develops in lungs with asymmetric compliance, which can lead to vital instability. The aim of this study was to investigate the respiratory dynamics and the effect of airway diameter on the distribution of tidal volume during mechanical ventilation in a lung model with asymmetric compliance.

Methods: Three groups of lung models were designed to simulate lungs with a symmetric and asymmetric compliance. The lung model was composed of two test lungs, lung1 and lung2. The static compliance of lung 1 in $\mathrm{C} 15, \mathrm{C} 60$, and $\mathrm{C} 120$ groups was manipulated to be 15,60 , and $120 \mathrm{ml} / \mathrm{cmH}_{2} \mathrm{O}$, respectively. Meanwhile, the static compliance of lung2 was fixed at $60 \mathrm{ml} / \mathrm{cmH}_{2} \mathrm{O}$. Respiratory variables were measured above (proximal measurement) and below (distal measurement) the model trachea. The lung model was mechanically ventilated, and the airway internal diameter (ID) was changed from 3 to $8 \mathrm{~mm}$ in 1-mm increments.

Results: The mean \pm standard deviation ratio of volumes distributed to each lung $\left(\mathrm{V}_{\mathrm{L} 1} / \mathrm{V}_{\mathrm{L} 2}\right)$ in airway ID $3,4,5,6,7$, and 8 were in order, $0.10 \pm 0.05,0.11 \pm 0.03,0.12 \pm 0.02,0.12 \pm 0.02,0.12 \pm 0.02$, and $0.12 \pm 0.02$ in the C15 group; $1.05 \pm 0.16,1.01 \pm 0.09,1.00 \pm 0.07,0.97$ $\pm 0.09,0.96 \pm 0.06$, and $0.97 \pm 0.08$ in the C60 group; and $1.46 \pm 0.18,3.06 \pm 0.41,3.72 \pm 0.37,3.78 \pm 0.47,3.77 \pm 0.45$, and $3.78 \pm 0.60$ in the $\mathrm{C} 120$ group. The positive end-expiratory pressure (PEEP) of lung1 was significantly increased at airway ID $3 \mathrm{~mm}\left(1.65 \mathrm{cmH} \mathrm{H}_{2} \mathrm{O}\right) \mathrm{in}$ the C15 group; at ID 3, 4, and $5 \mathrm{~mm}\left(2.21,1.06\right.$, and $\left.0.95 \mathrm{cmH}_{2} \mathrm{O}\right)$ in the $\mathrm{C} 60$ group; and ID 3, 4, and $5 \mathrm{~mm}\left(2.92,1.84\right.$, and $1.41 \mathrm{cmH} \mathrm{O}_{2} \mathrm{O}$ in the $\mathrm{C} 120$ group, compared to ID $8 \mathrm{~mm}(\mathrm{P}<0.05)$.

Conclusions: In the $\mathrm{C} 15$ and $\mathrm{C} 120$ groups, the tidal volume was unevenly distributed to both lungs in a positive relationship with lung compliance. In the C120 group, the uneven distribution of tidal volume was improved when the airway ID was equal to or less than $4 \mathrm{~mm}$, but a significant increase of PEEP was observed.

Key Words: airway obstruction; lung compliance; positive-pressure respiration, intrinsic; ventilation.

\section{Introduction}

Lung hyperinflation lowers the efficiency of the respiratory muscles by expanding the thorax and moves the diaphragm downwards, thus aggravating respiratory muscle fatigue [1]. In obstructive lung disease, the positive endexpiratory pressure (PEEP) is increased by airway obstruction during expiration, which leads to lung hyperinflation $[2,3]$. However, the mechanism of unilateral lung hyperinflation is more complex than bilateral lung hyperinflation. Unilateral

Received on August 17, 2016 Revised on March 1, 2017 Accepted on March 16, 2017

Correspondence to: Yong-Hun Lee, Department of Anesthesiology and Pain Medicine, Asan Medical Center, University of Ulsan College of Medicine, 88 Olympic-ro $43-$ gil, Songpa-gu, Seoul 05505, Korea

Tel: +82-2-3010-3879, Fax: +82-2-3010-6790, E-mail: yhlee0314@gmail.com

*No potential conflict of interest relevant to this article was reported.

(cc) This is an Open Access article distributed under the terms of the Creative Commons Attribution Non-Commercial License (http://creativecommons.org/ licenses/by-nc/4.0/) which permits unrestricted non-commercial use, distribution, and reproduction in any medium, provided the original work is properly cited. Copyright (c) 2017 The Korean Society of Critical Care Medicine 
lung hyperinflation is mainly caused by dynamic hyperinflation which is influenced by the lung compliance, tidal volume, airway resistance, and respiratory rate $[1,4]$. Asymmetric lung compliance aggravates unilateral lung hyperinflation. It may lead to mediastinal shift, giant bullae rupture, and acute vital instability. A typical example is native lung hyperinflation, which is one of the major complications associated with unilateral lung transplantation [5]. In addition, there have been reports of unilateral lung hyperinflation during mechanical ventilation of patients with chronic obstructive pulmonary disease (COPD), who had asymmetrical lung compliance due to fibrosis or pneumonia of a single lung [6,7]. Here, changes in ventilatory distribution caused by asymmetric lung compliance accelerated unilateral lung hyperinflation particularly in patients who had airflow obstruction [6]. To the best of our knowledge, little is known about the respiratory dynamics during mechanical ventilation of lungs with asymmetric compliance.

In the present study, we aimed to investigate the distribution of ventilatory volume during inspiration and the influence of airway internal diameter (ID) change, by measuring respiratory variables in an asymmetric lung compliance model.

\section{Materials and Methods}

\section{1) Lung model}

The lung model was set to simulate a patient mechanically ventilated under general anesthesia. An air filter, endotracheal tube with an ID of $8 \mathrm{~mm}$, connector with a variable diameter, Y-type breathing circuit, and two test lungs (Test lung 190; Maquet, Rastatt, Germany) were serially connected (Figure 1). The connector was placed to represent variable grades of distal airway obstruction. To implement asymmetrical lung compliance, one of the test lungs (lung1, $\mathrm{L}_{1}$ ) was manipulated to represent a normal lung $\left(\mathrm{C} 60\right.$, static compliance $\left.60 \mathrm{ml} / \mathrm{cmH}_{2} \mathrm{O}\right)$, a lung with low compliance (C15, static compliance 15 $\left.\mathrm{ml} / \mathrm{cmH}_{2} \mathrm{O}\right)$ or high compliance $(\mathrm{C} 120$, static compliance

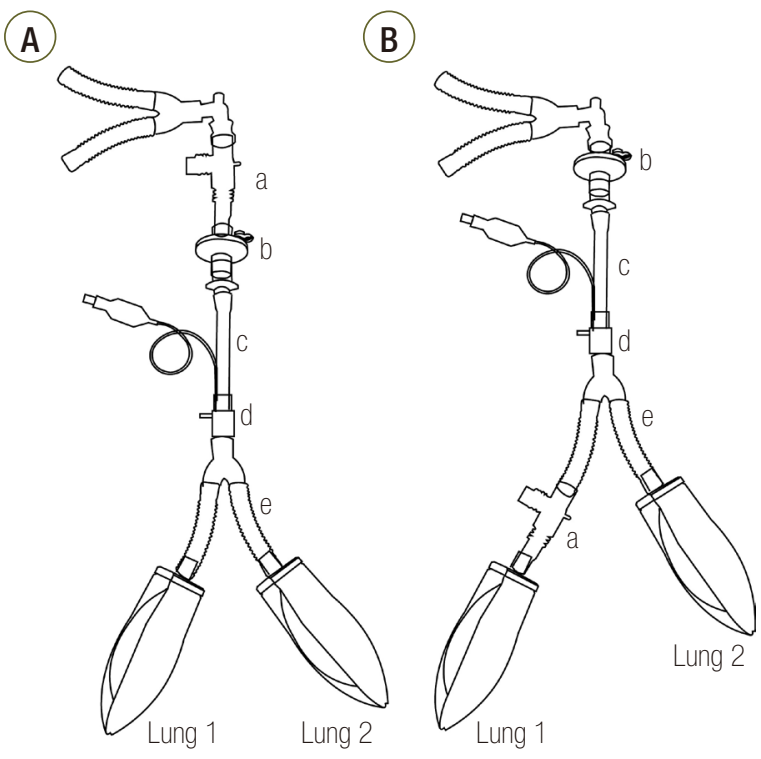

Figure 1. Schematic diagram of the two-lung model. (A) Proximal measurement setting. (B) Distal measurement setting. a: spirometer; b: filter; $c$ : endotracheal tube with an internal diameter of $8 \mathrm{~mm}$; d: connector with a variable internal diameter ranging from $3 \mathrm{~mm}$ to $8 \mathrm{~mm}$; e: breathing circuit.

$120 \mathrm{ml} / \mathrm{cmH}_{2} \mathrm{O}$ ). The compliance of the other test lung (lung2, $\mathrm{L}_{2}$ ) was set to that of a normal lung. In total, three lung models were constructed. To measure the respiratory parameters of total lung and $\mathrm{L}_{1}$, two spirometers (D-Lite $^{\mathrm{TM}}$; Datex-Ohmeda, Madison, WI, USA) were set between the breathing circuit and air filter (proximal measurement) and between the Y-type breathing circuit and $\mathrm{L}_{1}$ (distal measurement), respectively. The method described by Park et al. [8] was used to introduce compliance changes to $L_{1}$. At first, the cover plates of both test lungs were manipulated to establish a static compliance at $15 \mathrm{ml} / \mathrm{cmH}_{2} \mathrm{O}, 60 \mathrm{ml} / \mathrm{cmH}_{2} \mathrm{O}$, and $120 \mathrm{ml} / \mathrm{cmH}_{2} \mathrm{O}$. As a result, both plastic cover plates of the test lungs were either opened or fixed to establish a static compliance of 120 or $60 \mathrm{cmH}_{2} \mathrm{O}$, respectively, and 10 rubber bands were wound around the center of the fixed plastic cover plates to establish a static compliance of $15 \mathrm{cmH}_{2} \mathrm{O}$. Then, these conditions were applied to $\mathrm{L}_{1}$ of each group. Before measuring respiratory mechanics, proximally placed spirometer was used to observe static compliance. During the experiment, preset compliance changes were 
applied to $\mathrm{L}_{1}$. First, tidal volume of total lung and volumes distributed to each lung were measured proximally and distally, respectively. Second, other respiratory variables such as PEEP, plateau pressure time $\left(\mathrm{P}_{1}-\mathrm{P}_{2}\right.$ time $)$, and flow were measured proximally and distally.

\section{2) Intervention}

The lung model was ventilated using a mechanical ventilator (Dräger Fabius GS, Lübeck, Germany). Mechanical ventilation was performed using the volumecontrolled mode with an inspiration to expiration ratio $1: 2$, an oxygen flow of $4 \mathrm{~L} / \mathrm{min}$, a tidal volume of 600 $\mathrm{ml}$, a respiratory rate of 10 "breaths" per minute, and a maximum inspiratory pressure $<80 \mathrm{cmH}_{2} \mathrm{O}$. To observe the inspiratory plateau pressure, the inspiratory pause was set as $50 \%$ of the inspiration time ( 1 second). To measure the effect of airway ID change on the distribution of tidal volume during mechanical ventilation, the ID of the connector was decreased by $1-\mathrm{mm}$ intervals from 8 to $3 \mathrm{~mm}$. Every time the ID was changed, the new conditions were maintained for at least $1 \mathrm{~min}$ (10 cycles) before and 3 minutes ( 30 cycles) during data collection. A total of 36 conditions (three lung models, proximal and distal measurement, six IDs) were measured per cycle, and the mean values of 30 measurements at each condition (30 cycles) were calculated. Three additional cycles were measured with a spirometer distally placed at $\mathrm{L}_{2}$ to calculate the compliance ratio between the two lungs. The compliance ratio was calculated by dividing the mean values of $\mathrm{L}_{1}$ compliance by $\mathrm{L}_{2}$ compliance.

\section{3) Data collection}

A data collection computer program (S5 collect $^{\circledR}$; Datex-Ohmeda Co., Helsinki, Finland) was used to obtain physical variables at a frequency of $25 \mathrm{~Hz}$. Respiratory dynamics were analyzed based on this collected data. Flow, volume, and pressure were recorded as values measured by the spirometer, and static compliance was derived using the following equation:

$$
C_{\text {static }}=\frac{V_{T}}{P_{\text {plateau }}-P E E P} \quad \text { (equation1) }
$$

$\mathrm{C}_{\text {static }}$, static compliance; $\mathrm{V}_{\mathrm{T}}$, tidal volume; $\mathrm{P}_{\text {plateau, }}$ inspiratory plateau pressure; and PEEP, positive end-expiratory pressure. The time from the start $\left(\mathrm{P}_{1}\right)$ to the end $\left(\mathrm{P}_{2}\right)$ of the inspiratory plateau phase $\left(\mathrm{P}_{1}-\mathrm{P}_{2}\right)$ was calculated to evaluate the flow during the inspiratory pause.

\section{4) Statistical analysis}

Statistical analyses were performed using SPSS version 18.0 (SPSS Inc., Chicago, IL, USA). Differences between and within groups were analyzed using two-way and one-way analysis of variance (ANOVA), respectively. Post-hoc analyses were performed if the ANOVA results showed statistically significant differences. Depending on the results of Levene's test, a Bonferroni correction for equal variance or a Tamhane's T2 for unequal variance was used as the post-hoc test. The threshold for statistical significance in all tests was set at $\mathrm{P}<0.05$.

\section{Results}

The ratio of the volume distributed to the two lungs $\left(\mathrm{V}_{\mathrm{L} 1} / \mathrm{V}_{\mathrm{L} 2}\right)$ was proportionate to the ratio of lung compliance $\left(\mathrm{C}_{\mathrm{L} 1} / \mathrm{C}_{\mathrm{L} 2}\right)$ in all groups (Table 1). $\mathrm{V}_{\mathrm{L} 1} / \mathrm{V}_{\mathrm{L} 2}$ and $\mathrm{C}_{\mathrm{L} 1} / \mathrm{C}_{\mathrm{L} 2}$ were similar among the different airway IDs in $\mathrm{C} 15$ and $\mathrm{C} 60$ groups. However, in $\mathrm{C} 120$ group, $\mathrm{V}_{\mathrm{L} 1} / \mathrm{V}_{\mathrm{L} 2}(\mathrm{P}<0.001)$ and $\mathrm{C}_{\mathrm{L} 1} / \mathrm{C}_{\mathrm{L} 2}(\mathrm{P}<0.001)$ were significantly reduced at airway ID of 3 and $4 \mathrm{~mm}$ when compared with airway ID $8 \mathrm{~mm}$. The total tidal volume (volume proximally measured) and volume distributed to $\mathrm{L}_{1}$ is summarized in Table 2 .

The distally measured $\left(\mathrm{P}_{1}-\mathrm{P}_{2}\right)$ times were significantly shorter than those measured proximally in $\mathrm{C} 15$ and $\mathrm{C} 60$ group, except for an airway ID of $3 \mathrm{~mm}$ (Figure 2). The proximally measured $\left(\mathrm{P}_{1}-\mathrm{P}_{2}\right)$ times were comparable between groups (Figure $3 \mathrm{~A}$ ) and the distally measured $\left(\mathrm{P}_{1}-\mathrm{P}_{2}\right)$ time durations were negatively correlated to lung compliance (Figure 3B).

In the $\mathrm{C} 120$ group, a PEEP $>1 \mathrm{cmH}_{2} \mathrm{O}$ was observed for all IDs. PEEP was significantly increased for an 
Table 1. Comparison of $V_{L_{1}} / V_{L_{2}}$ and $C_{L_{1}} / C_{L_{2}}$ according to the airway internal diameter

\begin{tabular}{|c|c|c|c|c|c|c|}
\hline \multirow{2}{*}{ ID (mm) } & \multicolumn{2}{|c|}{ C15 group ${ }^{a}$} & \multicolumn{2}{|c|}{ C60 group ${ }^{b}$} & \multicolumn{2}{|c|}{ C120 group ${ }^{c}$} \\
\hline & $\mathrm{V}_{\mathrm{L} 1} \mathrm{~N}_{\mathrm{L} 2}$ & $\mathrm{C}_{\mathrm{L} 1} / \mathrm{C}_{\mathrm{L} 2}{ }^{\mathrm{d}}$ & $\mathrm{V}_{\mathrm{L} 1} N_{\mathrm{L} 2}$ & $\mathrm{C}_{\mathrm{L} 1} / \mathrm{C}_{\mathrm{L} 2}{ }^{\mathrm{d}}$ & $\mathrm{V}_{\mathrm{L} 1} N_{\mathrm{L} 2}$ & $\mathrm{C}_{\mathrm{L} 1} / \mathrm{C}_{\mathrm{L} 2}{ }^{\mathrm{d}}$ \\
\hline 3 & $0.10 \pm 0.05$ & 0.10 & $1.05 \pm 0.16$ & 1.05 & $1.46 \pm 0.18^{e}$ & 1.67 \\
\hline 4 & $0.11 \pm 0.03$ & 0.12 & $1.01 \pm 0.09$ & 1.03 & $3.06 \pm 0.41^{e}$ & 2.74 \\
\hline 5 & $0.12 \pm 0.02$ & 0.12 & $1.00 \pm 0.07$ & 1.02 & $3.72 \pm 0.37$ & 3.08 \\
\hline 6 & $0.12 \pm 0.02$ & 0.13 & $0.97 \pm 0.09$ & 1.00 & $3.78 \pm 0.47$ & 3.32 \\
\hline 7 & $0.12 \pm 0.02$ & 0.13 & $0.96 \pm 0.06$ & 1.00 & $3.77 \pm 0.45$ & 3.26 \\
\hline 8 & $0.12 \pm 0.02$ & 0.13 & $0.97 \pm 0.08$ & 1.00 & $3.78 \pm 0.60$ & 3.39 \\
\hline
\end{tabular}

Values are presented as mean \pm standard deviation or mean, as appropriate.

$V_{L_{1}}$ : volume distributed to lung1; $V_{L_{2}}$ : volume distributed to lung2; $C_{L 1}$ : static compliance of lung1; $C_{L 2}$ : static compliance of lung2; ID: internal diameter.

aStatic compliance of lung1 was manipulated as $15 \mathrm{ml} / \mathrm{cmH}_{2} \mathrm{O}$; 'Static compliance of lung1 was manipulated as $60 \mathrm{ml} / \mathrm{cmH}_{2} \mathrm{O}$; 'Static compliance of lung1 was manipulated as $120 \mathrm{ml} / \mathrm{CmH}_{2} \mathrm{O}$; 'Three additional cycles were measured with a spirometer distally placed at lung2 to calculate the compliance ratio between the two lungs;

${ }^{e} \mathrm{P}<0.05$ vs. airway internal diameter of $8 \mathrm{~mm}$.

Table 2. Difference of lung1 volume between groups at increasing internal diameters of airway

\begin{tabular}{|c|c|c|c|c|c|c|}
\hline \multirow{3}{*}{ ID (mm) } & \multicolumn{6}{|c|}{ Tidal volume (ml) } \\
\hline & \multicolumn{2}{|c|}{ C15 group ${ }^{a}$} & \multicolumn{2}{|c|}{ C60 group ${ }^{b}$} & \multicolumn{2}{|c|}{ C120 group ${ }^{c}$} \\
\hline & Total lung & Lung1 & Total lung & Lung1 & Total lung & Lung1 \\
\hline 3 & $524.6 \pm 25.8$ & $59.4 \pm 17.9$ & $530.5 \pm 19.0$ & $272.1 \pm 16.4$ & $551.0 \pm 17.1$ & $307.9 \pm 12.1^{d}$ \\
\hline 4 & $535.2 \pm 27.8$ & $55.2 \pm 10.2$ & $541.6 \pm 21.8$ & $272.4 \pm 9.3$ & $519.9 \pm 15.8$ & $401.6 \pm 16.0^{\circ}$ \\
\hline 5 & $541.5 \pm 28.8$ & $56.3 \pm 9.7$ & $549.3 \pm 24.4$ & $274.8 \pm 9.2$ & $534.8 \pm 17.1$ & $428.2 \pm 15.8$ \\
\hline 6 & $544.2 \pm 27.9$ & $60.4 \pm 4.7$ & $552.9 \pm 24.2$ & $272.6 \pm 8.9$ & $543.3 \pm 18.1$ & $432.7 \pm 18.9$ \\
\hline 7 & $544.7 \pm 27.8$ & $60.2 \pm 6.4$ & $557.3 \pm 23.4$ & $274.2 \pm 10.7$ & $547.2 \pm 19.0$ & $433.4 \pm 18.5$ \\
\hline 8 & $549.8 \pm 28.6$ & $59.3 \pm 8.1$ & $557.2 \pm 24.2$ & $274.9 \pm 10.0$ & $549.3 \pm 18.2$ & $433.7 \pm 20.4$ \\
\hline
\end{tabular}

Values are presented as mean \pm standard deviation.

ID: internal diameter.

${ }^{\text {aS }}$ Static compliance of lung1 was manipulated as $15 \mathrm{ml} / \mathrm{cmH}_{2} \mathrm{O}$; ' Static compliance of lung1 was manipulated as $60 \mathrm{ml} / \mathrm{cmH}_{2} \mathrm{O}$; 'Static compliance of lung1 was manipulated as $120 \mathrm{ml} / \mathrm{cmH}_{2} \mathrm{O}$; ${ }^{\mathrm{P}}<0.05$ vs. airway internal diameter of $8 \mathrm{~mm}$.

ID $\leq 5 \mathrm{~mm}$ (cross sectional area $\leq 19.6 \mathrm{~mm}^{2}$ ) compared with an ID of $8 \mathrm{~mm}$ in the $\mathrm{C} 120(\mathrm{P}<0.001)$ and $\mathrm{C} 60$ (P $<0.001)$. In the $\mathrm{C} 15$ group, a statistically significant increase of PEEP occurred in ID $3 \mathrm{~mm}$ (cross sectional area, $\left.7.1 \mathrm{~mm}^{2}\right)$, compared to ID $8 \mathrm{~mm}(\mathrm{P}<0.001)$. When the distal measurements of PEEP values were compared between lungs, C15 and C60 groups were comparable, while $\mathrm{C} 120$ group was significantly higher than that in the other models (Figure 4). Flow-time curve of distal measurement in the three groups are shown in Figure 5. The inspiratory flow of $\mathrm{L}_{1}$ in $\mathrm{C} 15$ and $\mathrm{C} 60$ groups was maintained $\leq 5$ and $\leq 10 \mathrm{ml} / \mathrm{s}$, respectively. This value was between 10 and $20 \mathrm{ml} / \mathrm{s}$ in the $\mathrm{C} 120$ group, showing the larger volume distributed to $\mathrm{L}_{1}$ compared to other groups.
Flow limitation was observed in smaller airway IDs, which was most significant in C120 group.

\section{Discussion}

Without airway obstruction, the tidal volume was distributed to each lung according to its compliance (Table 1). However, in the C120 group, although the total tidal volume was achieved, the volume distributed to $L_{1}$ was significantly decreased at ID 3 and $4 \mathrm{~mm}$, compared to ID $8 \mathrm{~mm}$ (Table 2). In visual inspection, a significant reduction of flow was observed in airway ID 3 and $4 \mathrm{~mm}$ in C120 group (Figure 5). 

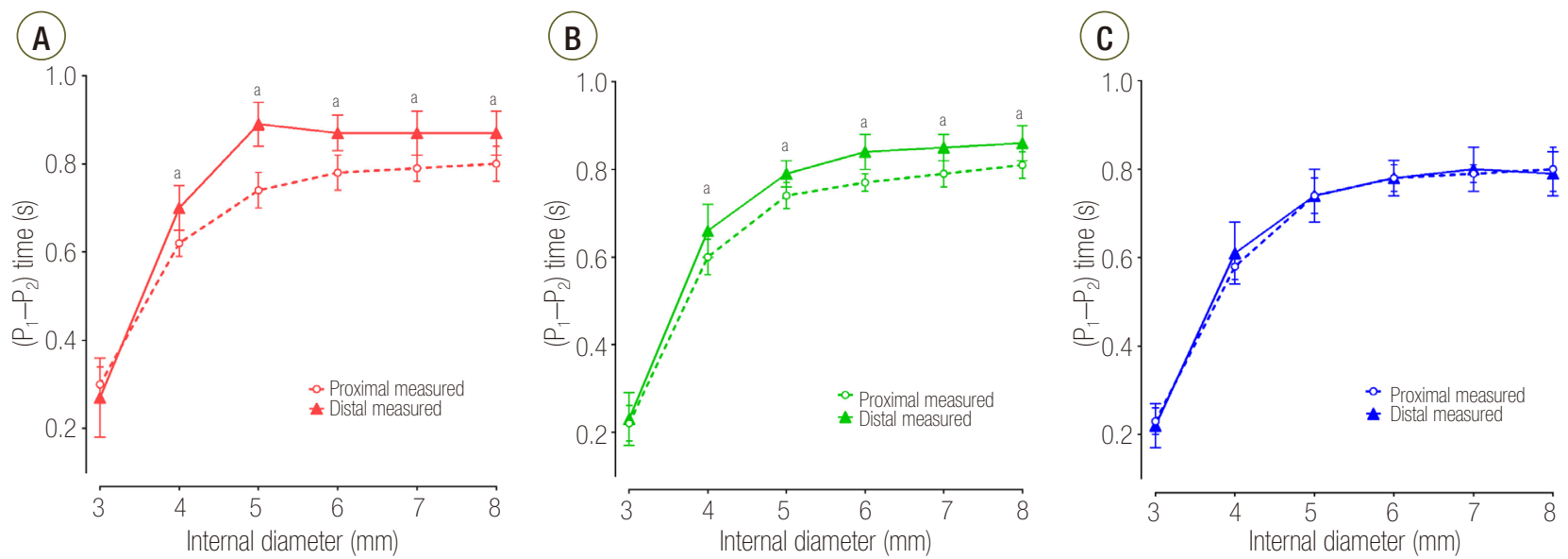

Figure 2. Change of plateau pressure time in (A) $C 15$, (B) C60, and (C) $C 120$ groups. $P_{1}$ : start point of plateau pressure; $P_{2}$ : end point of plateau pressure; $\mathrm{C} 15$ : static compliance of lung1 was manipulated as $15 \mathrm{ml} / \mathrm{cmH}_{2} \mathrm{O}$; $\mathrm{C} 60$ : static compliance of lung1 was manipulated as $60 \mathrm{ml} / \mathrm{cmH}_{2} \mathrm{O}$; $\mathrm{C} 120$ : static compliance of lung1 was manipulated as $120 \mathrm{ml} / \mathrm{cmH}_{2} \mathrm{O} .{ }^{a} \mathrm{P}<0.05 \mathrm{vs}$. proximal measurement.
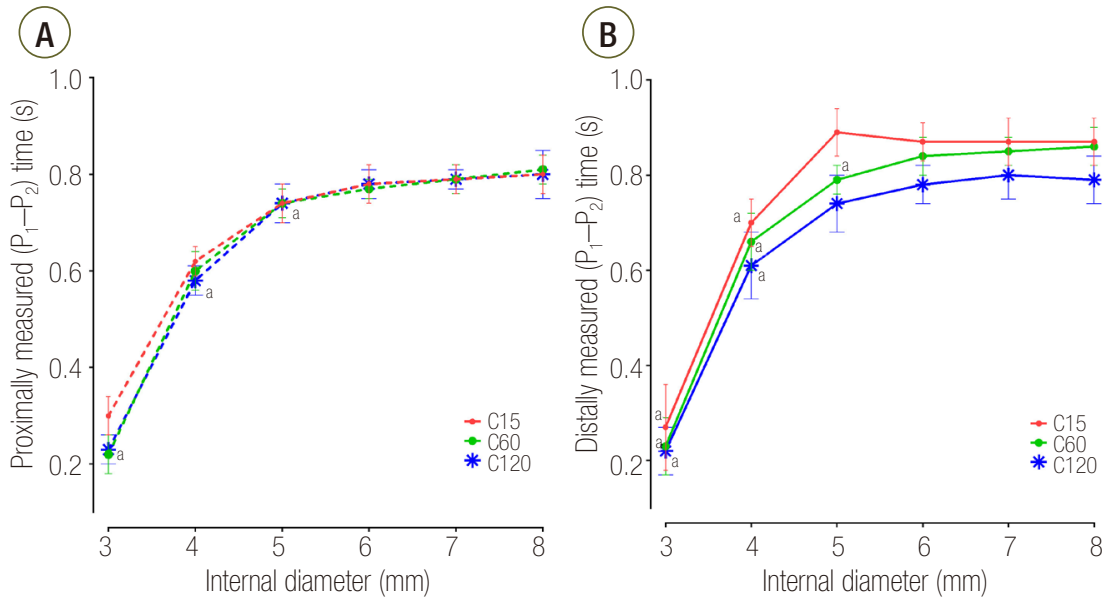

Figure 3. Change of plateau pressure time at (A) proximal and (B) distal measurements during change of internal diameter. $P_{1}$ : start point of plateau pressure; $P_{2}$ : end point of plateau pressure; $\mathrm{C} 15$ : static compliance of lung1 was manipulated as $15 \mathrm{ml} /$ $\mathrm{CmH}_{2} \mathrm{O} ; \mathrm{C} 60$ : static compliance of lung1 was manipulated as $60 \mathrm{ml} / \mathrm{cmH}_{2} 0 ; \mathrm{C} 120$ : static compliance of lung1 was manipulated as $120 \mathrm{ml} / \mathrm{cmH}_{2} \mathrm{O}$. ${ }^{\text {ap }}<0.05$ vs. airway internal diameter of $8 \mathrm{~mm}$.

While other groups did not show a significant reduction in the tidal volume distributed to $\mathrm{L}_{1}$, the distal measurement in C120 did show indications of statistically significant decreases at airway ID values of 3 and $4 \mathrm{~mm}$ (Table 2). The proportion of tidal volume distributed to $L_{1}$ in the C120 group was reduced at airway ID 3 and $4 \mathrm{~mm}$. This signifies amelioration of the asymmetry of ventilatory distribution, which can be explained by a few factors.

First, differences in the expansion rates of both lungs can be inferred by the differences of the time constants according to their compliance. The time constant is a product of the compliance and resistance and is therefore proportional to both compliance and resistance. Assuming that the resistances of both lungs are similar, the time constants of both lungs are proportional to their compliance. Having a small time constant means increased speed and pressure since the equilibrium volume is reached more quickly, and flow to that compartment will stop earlier. Meanwhile, having a larger time constant means that the time to reach the equilibrium volume is longer, and flow to that compartment will persist longer until equilibrium volume is reached [9-11]. Differences in time constants according to the differences in compliance can be confirmed by the $\left(\mathrm{P}_{1}-\mathrm{P}_{2}\right)$ time results (Figure $3 \mathrm{~B})$. When distally measured, $\left(\mathrm{P}_{1}-\mathrm{P}_{2}\right)$ times were significantly longer than proximally measured values in C15 and C60 groups; however, distally measure $\left(\mathrm{P}_{1}-\mathrm{P}_{2}\right)$ times of $\mathrm{C} 120$ group were comparable with proximally 
measured values (Figure 2). From this finding, it can be inferred that the flow at $\mathrm{L}_{1}$ stops earlier than proximal measurement in the $\mathrm{C} 15$ and $\mathrm{C} 60$ groups. But in the C120 group, the flow at $\mathrm{L}_{1}$ persists until the flow at the

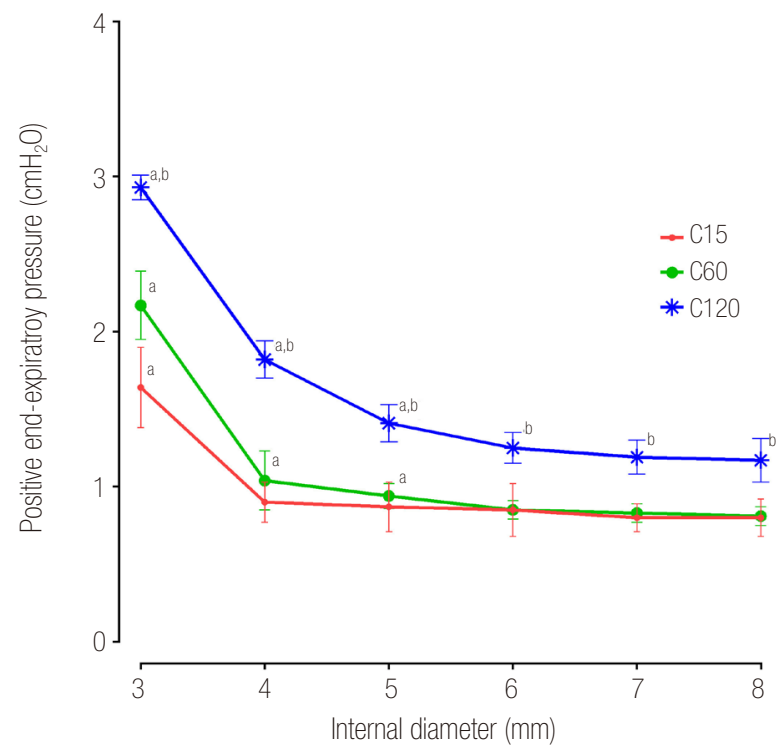

Figure 4. Distal measurements showing response of positive endexpiratory pressure according to internal diameter change. C15: static compliance of lung1 was manipulated as $15 \mathrm{ml} / \mathrm{cmH}_{2} \mathrm{O}$; C60: static compliance of lung1 was manipulated as $60 \mathrm{ml} / \mathrm{cmH}_{2} \mathrm{O} ; \mathrm{C} 120$ : static compliance of lung1 was manipulated as $120 \mathrm{ml} / \mathrm{cmH}_{2} \mathrm{O}$. ${ }^{\mathrm{a}} \mathrm{P}<0.05$ vs. airway internal diameter of $8 \mathrm{~mm}$. Cross section area: internal diameter of $3,4,5,6,7$ and $8 \mathrm{~mm}$ were measured to be 7.1, 12.6, 19.6, 28.3, 38.5, $50.3 \mathrm{~mm}^{2}$ respectively; ${ }^{\mathrm{b}} \mathrm{P}<0.05$ vs. $\mathrm{C} 60$ group. proximal measurement stops, indicating that $\mathrm{L}_{1}$ in this group may not have enough time to reach the equilibrium volume distributed according to the compliance.

Second, a decrease in the airway ID causes a limitation of flow and increases the time required for the lungs to reach their equilibrium volume. When the flow rate decreases, the time required to fill a certain lung volume is increased, which makes it more difficult for the lung with the larger time constant (i.e., the lung with higher compliance if the airway resistance is the same) to fill the same volume. The flow-time curve of the three distally measured groups (Figure 5) shows that at an airway ID was equal to or less than $4 \mathrm{~mm}$, all groups failed to reach the tidal volume within the inspiration period.

It is widely known that reducing the tidal volume and respiration rate ameliorates lung hyperinflation, and these variables can be controlled by mechanical ventilators [12-14]. This is true even in the asymmetrical lung compliance cases in COPD patients reported by Kollef and Turner [6]. However, little is known about how airway diameter changes, such as those in airway obstruction, affect unilateral lung hyperinflation. Anglès et al. [15] reported that after unilateral lung transplantation, the incidence of hyperinflation in the remaining native lung reached $64 \%$ during hospitalization. Lung hyperinflation led to longer ICU stays and higher mortality rates $(67 \%$
(A)

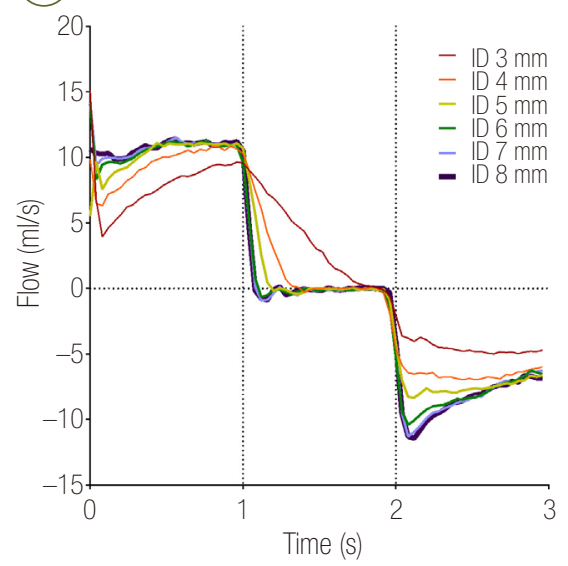

(B)

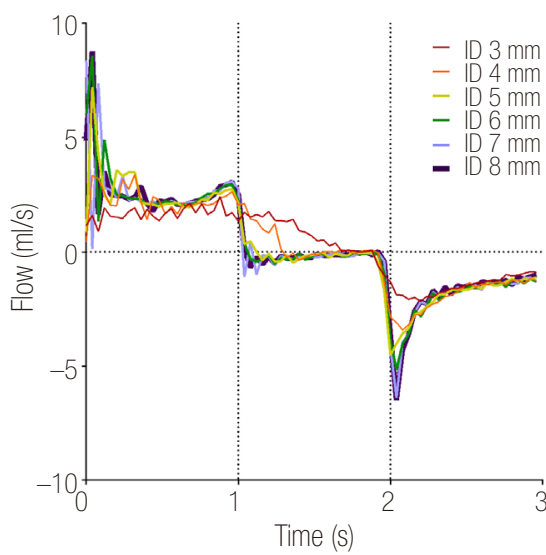

(C)

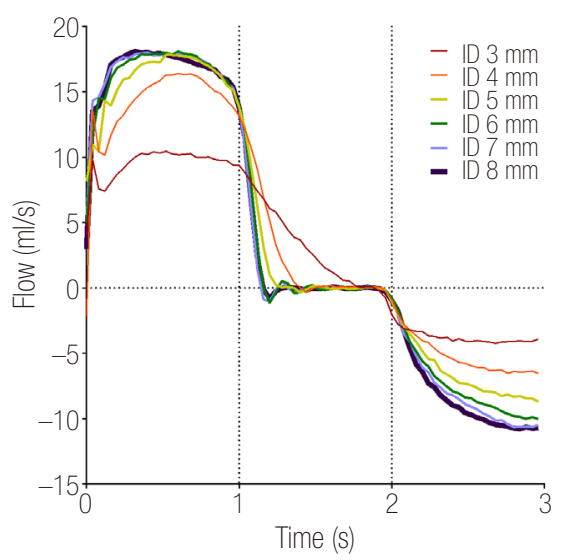

Figure 5. Flow-time curve of distal measurement in (A) C15, (B) C60, and (C) $\mathrm{C} 120$ groups. The area under the curve represents volume distributed to lung1. ID: internal diameter; $\mathrm{C} 15$ : static compliance of lung1 was manipulated as $15 \mathrm{ml} / \mathrm{cmH}_{2} 0$; $\mathrm{C} 60$ : static compliance of lung1 was manipulated as $60 \mathrm{ml} / \mathrm{cmH}_{2} \mathrm{O}$; C120: static compliance of lung1 was manipulated as $120 \mathrm{ml} / \mathrm{cmH}_{2} \mathrm{O}$. 
vs. $20 \%$ ) compared with patients without lung hyperinflation.

The results of the present study can be applied to patients under these conditions. However, improving the ventilatory distribution by reducing the airway ID $\leq 4 \mathrm{~mm}$ is not a desirable treatment for the mechanical ventilation of COPD patients with asymmetrical lung compliance. Because PEEP was significantly increased for an airway ID $\leq 5 \mathrm{~mm}$, reducing the airway ID $\leq 4 \mathrm{~mm}$ may further exacerbate auto-PEEP. Clinical applications to limit volume redistribution in lungs with asymmetric compliance should focus on appropriate flow limitations that can maximize the time constant difference between the two lungs or on reducing the inspiratory pause time. The appropriate inspiratory flow rate for a patient may vary depending on the ratio of inspiration to expiration, respiratory rate, appropriate tidal volume, and lung compliance. As such, additional clinical studies are required to elucidate the appropriate values of these variables.

The limitation of our experimental model is that the model does not reflect the airway obstruction that occurs during expiration in obstructive lung disease. As such, our results should be limited to demonstrating the mechanism of unilateral lung hyperinflation during inspiration. Moreover, although the effects of respiratory muscles were not taken into account by assuming mechanical ventilation under general anesthesia, the interactions that may occur between both lungs due to the limited space of the thoracic cavity were not considered. Therefore, the measured values in the present study should be regarded as relative values showing the relationship between respiratory mechanical variables rather than absolute values. On the other hand, the fact that the respiratory variables were measured separately in unilateral lungs is a significant advantage of the present study as compared with animal studies or clinical trials.

In conclusion, we were able to show that the distribution of volume during inspiration was positively correlated to lung compliance. The uneven distribution of volume might be reduced by changing the airway diameter equal to or less than $4 \mathrm{~mm}$ (cross sectional area, 12.6 $\mathrm{mm}^{2}$ ); however, this may exacerbate auto-PEEP.

\section{Acknowledgments}

This study was presented at the Critical Care Symposium of the World Federation of Societies of Intensive and Critical Care Medicine (WFSICCM) on August 31, 2015 in Seoul, Korea.

\section{ORCID}

So Hui Yun

http://orcid.org/0000-0001-9544-5085

Yong-Hun Lee

http://orcid.org/0000-0002-1724-7996

Jong Cook Park

\section{References}

1. Fitting JW. Respiratory muscles in chronic obstructive pulmonary disease. Swiss Med Wkly 2001;131:483-6.

2. Ahmed SM, Athar M. Mechanical ventilation in patients with chronic obstructive pulmonary disease and bronchial asthma. Indian J Anaesth 2015;59:58998.

3. Caramez MP, Borges JB, Tucci MR, Okamoto VN, Carvalho CR, Kacmarek RM, et al. Paradoxical responses to positive end-expiratory pressure in patients with airway obstruction during controlled ventilation. Crit Care Med 2005;33:1519-28.

4. Lumb AB. Nunn's applied respiratory physiology. 7th ed. London: Churchill Livingstone; 2010.

5. Venuta F, Boehler A, Rendina EA, De Giacomo T, Speich R, Schmid R, et al. Complications in the native lung after single lung transplantation. Eur J Cardiothorac Surg 1999;16:54-8.

6. Kollef MH, Turner JF. Intrinsic PEEP and unilateral lung hyperinflation: pathophysiology and clinical significance. Chest 1992;102:1220-4.

7. Eveloff SE, Rounds S, Braman SS. Unilateral lung hyperinflation and herniation as a manifestation of 
intrinsic PEEP. Chest 1990;98:228-9.

8. Park SH, Yun SH, Park JC. Effects of upper airway obstruction on respiratory mechanics in a variable compliance model. Anesth Pain Med 2011;6:244-8.

9. Al-Rawas N, Banner MJ, Euliano NR, Tams CG, Brown J, Martin AD, et al. Expiratory time constant for determinations of plateau pressure, respiratory system compliance, and total resistance. Crit Care 2013;17:R23.

10. Melo e Silva CA, Ventura CE. A simple model illustrating the respiratory system's time constant concept. Adv Physiol Educ 2006;30:129-30.

11. Hess DR. Respiratory mechanics in mechanically ventilated patients. Respir Care 2014;59:1773-94.

12. Schumaker GL, Epstein SK. Managing acute respira- tory failure during exacerbation of chronic obstructive pulmonary disease. Respir Care 2004;49:766-82.

13. O'Donnell DE, Revill SM, Webb KA. Dynamic hyperinflation and exercise intolerance in chronic obstructive pulmonary disease. Am J Respir Crit Care Med 2001;164:770-7.

14. Puente-Maestu L, García de Pedro J, Martínez-Abad Y, Ruíz de Oña JM, Llorente D, Cubillo JM. Dyspnea, ventilatory pattern, and changes in dynamic hyperinflation related to the intensity of constant work rate exercise in COPD. Chest 2005;128:651-6.

15. Anglès R, Tenorio L, Roman A, Soler J, Rochera M, de Latorre FJ. Lung transplantation for emphysema. Lung hyperinflation: incidence and outcome. Transpl Int 2005;17:810-4. 